\title{
Fuzzy Logic Based Career Guidance System
}

\author{
Akshay U. Kulkarni, Amit M. Potadar, Amogh R. Gaonkar and Amresh Kumar
}

\begin{abstract}
We propose a solution to help the students in selecting the right career path using web based application. The project aims to use a fuzzy logic based simple mechanism to build an interactive web based system to help the student community in making the right career choice. The web based application will be available for use with some basic registration required by the user. The project helps out the user to analyze his preliminary abilities to convert probable real life career selection. As the application is based on selfanalyzation, we feel that it will have a real impact on the user.
\end{abstract}

\section{INTRODUCTION}

$\mathrm{C}$ AREER can be defined as a gateway to shape the life with proper selection of a path based on individual's personality or a person's course or progress through life (or a distinct portion of life). Here, career is understood to relate to a range of aspects of an individual's life, learning and work. Career is also frequently understood to relate to the working aspects of an individual's life. A third way in which the term career is used to describe an occupation or a profession that usually involves special training or formal education and is considered to be a person's lifework. Recommendation systems are commonly used over the Internet to guide customers to find the products or services that best fit with their personal preferences. For example, customers buying an electronic gadget such as a mobile phone use a recommendation system to help in selecting the best model which fulfills the needs of the customer and at the same time is within the budget. To recommend the best product, the system needs specific input from the customer.

Due to rapid development of the society, the career opportunities have increased. Keeping in mind present various/plenty career opportunities available, the students puzzle themselves while selecting the right path unless otherwise determined, i.e. choosing a career is a difficult decision due to the existence of multiple human abilitieswhich mean each person or human has their ability or skill at the certain area and can be applied to multiple job careers.

There are several factors that influenced the students when choosing their career path such as their personal aptitudes,

Akshay U. Kulkarni, B.E, Department of Computer Science and Engineering, SDM College of Engineering and Technology, Dharwad, India. E-mail:akulkarni608@gmail.com

Amit M. Potadar, B.E, Department of Computer Science and Engineering, SDM College of Engineering and Technology, Dharwad, India. E-mail:amitpotdar31@gmail.com

Amogh R. Gaonkar, B.E, Department of Computer Science and Engineering, SDM College of Engineering and Technology, Dharwad, India. E-mail:amoghgaonkar.61@gmail.com

Amresh Kumar, B.E, Department of Computer Science and Engineering, SDM College of Engineering and Technology, Dharwad, India. E-mail:amardeep12sept@gmail.com

DOI:10.9756/BIJSESC.8230 educational achievement and their environment. Upon completing their first degree or undergraduate students at the university, students are normally starting to consider a career path which may suit their skill and potential the best. However, many students made wrong decision on selecting their career due to the lack of experience, help and advice from friends and relatives, parents and lecturers, or career counselling. The wrong decisions made by students may potentially cause mismatch between academic achievements, personality, interest and abilities of them. So, to help the students in puzzle state of mind because of various constraints/interests/academic strength/economic reach out etc. or to recommend them in career selection, the solution to build a recommendation system that provides direction and guidance to students in choosing their career has been arrived at. Hence, this project proposes to design and develop a career recommendation system driven by fuzzy logic technique.

Fuzzy logic is an approach to computing based on "degrees of truth" rather than the usual "true or false" ( 1 or 0$)$ Boolean logic on which the modern computer is based. Fuzzy logic has been extended to handle the concept of partial truth, where the truth value may range between completely true and completely false. Furthermore, when linguistic variables are used, these degrees may be managed by specific functions. The use of fuzzy logic approach helps students by giving career recommendation based on career test. Based on conventional method that have been applied, they just focus to one career option without look up the other potential career options that also can be match with their skills or abilities. By integrating fuzzy logic system with career guidance option on web based aid, it'll help to get multiple ways based on their solving ability. The web based fuzzy logic questioner is in such a way that it creates interest/introspect himself where he can have a guiding career path for the answers he has chosen. Hence, to give a proper probable aid for career selection, the web based fuzzy logic goes very useful. So by implementing this system it gives a better result and also students can involve with his system.

\section{A. Problem Definition}

The "Fuzzy Logic Based Career Guidance System" aims to use a fuzzy logic based simple mechanism to build an interactive web based system to help the student community in making the right career choice, who have puzzled themselves.

\section{B. Purpose}

The purpose of this document is to present a detailed description of our Web Application. It will explain the purpose and features of the application, what the application works for, the constraints under which it must operate and how the application works. This document is intended for both the client and the developers of the system and will be 
proposed to the SDMCET CSE Mini Project Review Committee for its approval.

\section{Project Scope}

We expect that the project really helps out the user to analyze his preliminary abilities to convert probable real life career selection. It is a very simple and immediate usable application. As the application is based on self-analyzation, we feel that it'll have a real impact on the user.

\section{Objectives}

- To help students understand and develop the necessary skills to equip them for whatever career path they choose.

- To provide opportunities for students to understand their competencies, aspirations and options.

- To sharpen their career and future

- To make them aware of choosing the right career option or the appropriate course according to their aptitude.

\section{METHODOLOGY AND SYSTEM STUDY} below:

The steps for the implementation of the system go as given

\section{A. Data Collection}

The system proposed based on the data collected among the group of our students who have gone through the phase of career selections, questions arised in their mind, looking for the proper solution, ease of getting the method, etc. Then again further we have looked into data available in the internet/books/project literatures/columns appearing the newspapers during every beginning of the academic sessions etc.

\section{B. Analysis}

Based on the available data, the logical analysis has been put in the form of questionnaire. Each question is related has a logical conclusion for selecting the number in the scale. The questions prepared are based on his academic performance, interest in the subjects, ongoing trends, real-time thinking, etc. These summarized logical answers will be analyzed for the probable result. The proposed system is a web based system which implements a 3 tier architecture comprising of the database tier, the application tier in the middle and the client tier.

\section{Literature Survey}

Fuzzy logic has been extended to handle the concept of partial truth, where the truth value may range between completely true and completely false. Fuzzy logic based career selection by author Tajul Rosli Razak et al [1] from Universiti Teknologi MARA (Perlis), Malaysia has been proposed and was published in international journals.

The authors are faculties of Computer and Mathematical Science, Universiti Teknologi MARA (Perlis), Malaysia. They have skills and expertise in image processing, fuzzy logic, machine learning, neural networks, artificial intelligence, soft computing, MATLAB, pattern recognition, etc. The reference work we have taken, has a counsellor as a domain expert and a computer based solution to help to obtain the data about skill and personality for each career path. There mapping process involves input and output membership functions, fuzzy logic operators, fuzzy if then rules, aggregation of output sets, and defuzzification. There work has been basically divided into 3 subparts as fuzzification, fuzzy inference and defuzzification. The fuzzification part contains input of 2 parts as skills and personality. Then there is a interview taken with students by the counsellor and based on 0-10 scale the students are reviewed and classified into corresponding skills based on the questions focusing on $11 \%$ of personality and remaining with their skill. Further the range is divided into 3 parts as weak, medium, good as per their skills and then again divided into linguistic variables as no, maybe, yes according to each skill. The crisp values of each scale of skill are converted to the fuzzy value in range $\{0,1\}$ and then represented in graph. The fuzzy inference part formulates the mapping of an input function to an output function using the fuzzy logic. It uses the Fuzzy Associate Memory(FAM) technique which is used to reach nearly to control objectives by evaluating the linguistic variables. The defuzzification part, where the fuzzy output variables are translated to the min value. It creates the best possible single value that can represent the inferred fuzzy value at its best.

Our project is based on self help system to assess themselves to have a probable clear path which may sometimes eliminate further counselling. It is one-to-one based i.e. individual and computer interaction where students can answer the logical questions to get initial solution for their path or career. We have projected the clear picture of how to interact/introspect/think the logical answers/select the scale to arrive at results in the further explained methodology area.

\section{Proposed Work}

The proposed project shall be developed as an independent web based application which can be hosted on a web server on the Internet. The project can be developed using server side scripting technologies. Various scripting languages were analyzed and it was decided to select PHP as the language for server side scripting. Data storage shall be done in MySQL database. The front-end design shall be implemented using a combination of HTML and CSS. JavaScript shall also be used to enhance the user experience in terms of usability and error checking.

\section{E. Specifications}

\section{Hardware Specifications}

The hardware requirements for the development of this project are listed below.

\begin{tabular}{|l|l|}
\hline Processor & Intel Pentium Core 2 Duo or above \\
\hline RAM & 2GB RAM or above \\
\hline Hard Disk & $80 \mathrm{~GB}$ or above \\
\hline Processor Speed & $2.0 \mathrm{GHz}$ or above \\
\hline
\end{tabular}

\section{Software Specifications}

The software requirements for the development of this project are listed below. 


\begin{tabular}{|l|l|}
\hline Operating System & Windows 7 / Windows 8 \\
\hline Web design & HTML, CSS \\
\hline Server Side Scripting & PHP \\
\hline Client Side Scripting & JavaScript \\
\hline Database & MySQL \\
\hline Web server & Apache Tomcat Server \\
\hline Tools & WAMP Server \\
\hline
\end{tabular}

F. Technical Requirements

- Scalability: Since the application just demonstrates our proposed theory for this application .This application can be used on a much larger scale after developing the application further.

- Supportability: The application shall require the installation of Wamp server. The application shall allow additional tools to be added on the completion of the minimum requirements.

- Reliability: In a case of the application malfunctioning the user need not have to worry about the data being lost or corrupted as it is always stored in a text document. And if server is lost then the problem of working of code may occur since php mainly works on Wamp server.

- Availability: The basic version of the server shall be ready for use without any downtime, and application will be ready with no down time.

\section{IMPLEMENTATION}

\section{A. Implementation Modules}

The proposed web based project shall have different modules for better implementation and maintenance. The modules identified are given below.

- User Module

- Data-analyzing Module

In the User Module, the system will be designed with a simple user/student registration, i.e. a simple registration page shall be provided for registration by providing the details, loging with registered username and password for entering the system, selecting one of the available tests, to decide whether the career stream is a right choice for the registered user, answering the questions in the tests consisting of different parts, checking the score/number of each part in the scale for selecting the right career.

The Data-analyzing Module is a tool to satisfy the user himself that the conclusion arrived by solving the fuzzy logic is really helpful.

Connection of these in between with simple diagrams :

- Here the information stored in database can be accessed by client side by server program as intermediate.

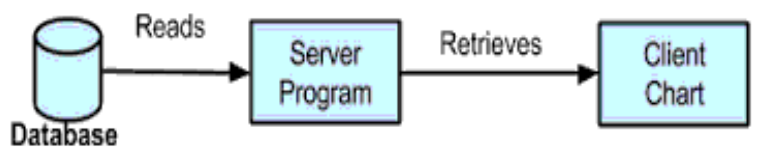

Figure 1: Connection between Database and Client Side through Server Program

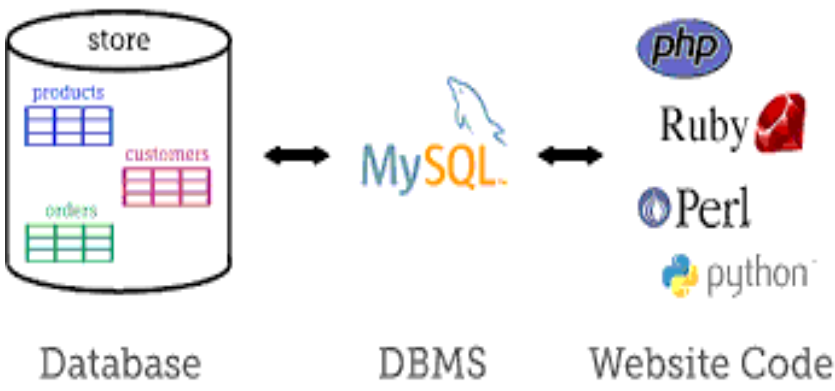

Figure 2: Here Database MySQL and Server are Interrelated as Information on Web Side can be Stored on MySQL

\section{CONCLUSION}

Student Specific

- As a student, the project helps in the learning stage itself the execution, involvement, creativeness and the process of project.

- It also helps in correctness of the future for the critics raised by the observer.

- We also learn about the tools like WAMP Server, Apache Tomcat Server and database like ORACLE $10 \mathrm{G}$.

- We also learn about the interfacing of the system, integration and interpretation of the process.

- We learn the languages like Java, Android, HTML, CSS, PHP.

Project Specific

- We expect that the project really helps out the user to analyze his preliminary abilities to convert probable real life career selection.

- It is a very simple and immediate usable application.

- As the application is based on self-analyzation, we feel that it'll have a real impact on the user.

\section{ACKNOWLEDGEMENT}

Mentors make a difference! Our heartfelt thanks goes to our guide Prof. Bhargavi Mokashi, Dr. S B Kulkarni, Department of Computer Science and Engineering, SDMCET, Dharwad, who has been most supportive and helpful in completion of this project. She had confidence in us when we doubted ourselves and brought out the good ideas in us.

We are greatly thankful to Dr. S M Joshi, H.O.D, Department of Computer Science and Engineering, SDMCET, Dharwad, who always shows a keen interest to help out anyone at any time. Without his encouragement and constant gratitude, we could not have finished these dissertation.

We are greatly thankful to Prof. Anand Vaidya and Prof. R N Yadawad, Department of Computer Science and Engineering, SDMCET, Dharwad, the coordinators of mini-project who encouraged us at several point of time providing invaluable ideas and helping us on our presentation skills, improving document format and standards which helped us a lot in completion of this report in the best way. 


\section{REFERENCES}

[1] T.R. Razak, M.A. Hashim, N.M. Noor, I.H.A. Halim and N.F.F. Shamsul, "Career path recommendation system for UiTM Perlis students using fuzzy logic", International Conference on Intelligent and Advanced Systems (ICIAS), Pp. 1-5, 2014.

[2] ResearchGate:www.researchgate.net/profile/Tajul_Rosli_Razak/publicat ions

[3] T.R.Razak, "Fuzzy Logic System and its working", ResearchGate.

[4] M.A. Talib and T.K. Aun, "Predictors of Career Indecision Among Malaysian Undergraduate Students", European Journal of Social Sciences, Vol. 8, No. 2, 2009.

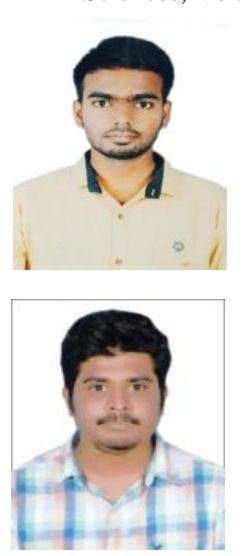

Akshay U. Kulkarni

Date of Birth : 07/04/1995

Place : Dharwad

Designation : B.E, SDM College of Engineering \& Technology, Dharwad.

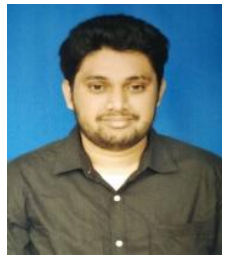

\section{Amit M. Potadar}

Date of Birth : 01/03/1995

Place : Hubli

Designation : B.E, SDM College of Engineering \& Technology, Dharwad.

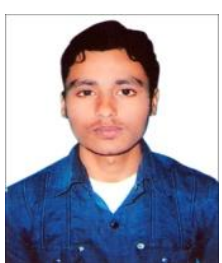

\section{Amogh R. Gaonkar}

Date of Birth : 12/08/1995

Place : Hubli

Designation : B.E, SDM College of Engineering \& Technology, Dharwad.

\section{Amresh Kumar}

Date of Birth : 12/09/1995

Place

: Dharwad

Designation : B.E, SDM College of Engineering \& Technology, Dharwad. 